\title{
Pomalidomide promotes chemosensitization of pancreatic cancer by inhibition of NF-KB
}

\author{
Yoshihiro Shirai, ${ }^{1,2}$, Nobuhiro Saito ${ }^{1,2, *}$, Tadashi Uwagawa ${ }^{1,3}$, Hiroaki Shiba ${ }^{1}$, Takashi \\ Horiuchi $^{1,2}$, Ryota Iwase ${ }^{1}$, Koichiro Haruki ${ }^{1}$, Toya Ohashi ${ }^{2}$ and Katsuhiko Yanaga ${ }^{1}$ \\ ${ }^{1}$ Department of Surgery, The Jikei University School of Medicine, Tokyo, Japan \\ ${ }^{2}$ Division of Gene Therapy, Research Center for Medical Sciences, The Jikei University School of Medicine, Tokyo, Japan \\ ${ }^{3}$ Division of Clinical Oncology and Hematology, Department of Internal Medicine, The Jikei University School of Medicine, \\ Tokyo, Japan \\ *This author contributed equally to this work \\ Correspondence to: Yoshihiro Shirai, email: shirai@jikei.ac.jp \\ Toya Ohashi, email: tohashi@jikei.ac.jp \\ Katsuhiko Yanaga, email: kyanaga@jikei.ac.jp \\ Keywords: pancreatic cancer; pomalidomide; NF-KB; gemcitabine; 1 \\ Received: September 05, 2017 Accepted: February 21, 2018 Epub: February 26, 2018 Published: March 16, 2018 \\ Copyright: Shirai et al. This is an open-access article distributed under the terms of the Creative Commons Attribution License 3.0 \\ (CC BY 3.0), which permits unrestricted use, distribution, and reproduction in any medium, provided the original author and source \\ are credited.
}

\section{ABSTRACT}

Introduction: Nuclear factor KB (NF-KB) plays an important role in cancer progression and causes therapeutic resistance to chemotherapy. Pomalidomide, a third-generation immunomodulating drug derived from thalidomide, has been approved for uncontrolled multiple myeloma. We hypothesized that pomalidomide may inhibit the anticancer agent-induced NF-KB activity and enhance chemosensitization of combination chemotherapy with gemcitabine and S1 (Gem/S1) in pancreatic cancer.

Methods: In vitro, we assessed NF-KB activity, induction of caspase cascade, cell apoptosis and cell proliferation using human pancreatic cancer cell lines (MIA PaCa2 and PANC-1). In vivo, we established an orthotopic xenograft mouse model for human pancreatic cancer by injection of PANC-1 cells. At 5 weeks after injection, the animals were randomly divided into four groups and treated with $\mathrm{Gem}(100 \mathrm{mg} / \mathrm{kg})$ /S1 $(10 \mathrm{mg} / \mathrm{kg})$, with oral administration of pomalidomide $(0.5 \mathrm{mg} / \mathrm{kg})$, with combination of gemcitabine, S1, and pomalidomide or vehicle only.

Results: Although chemotherapeutic agents induced NF-KB activation in pancreatic cancer cells, pomalidomide inhibited anticancer agent-induced NF-KB activation ( $p$ $<0.01$ ). Of the four groups tested for the apoptosis-related caspase signals and apoptosis under both in vitro and in vivo conditions, Gem/S1/Pomalidomide group demonstrated the strongest activation of the caspase signals and proapoptotic effect. In Gem/S1/Pomalidomide group, cell proliferation and tumor growth were slower than those in other groups both in vitro and in vivo $(p<0.01)$. There were no obvious adverse effects except for thrombocytosis by using pomalidomide.

Conclusions: Pomalidomide promotes chemosensitization of pancreatic cancer by inhibiting chemotherapeutic agents-induced NF-kB activation. 


\section{INTRODUCTION}

Pancreatic cancer is the fourth leading cause of death in developed countries [1]. At the time of diagnosis, one-half of the patients present with metastatic disease and approximately $30 \%$ with unresectable locally advanced disease [2]. In addition, because of the rapid tumor growth and the high metastatic potential, the overall 5-year relative survival rate was only $10 \%$ [3]. Recently, the combination chemotherapy of gemcitabine and $\mathrm{S} 1(\mathrm{Gem} /$ $\mathrm{S} 1$ ) is one of the most effective regimens for the treatment of locally advanced and metastatic pancreatic cancer in Korea and Japan [4]. However, the objective response rate of $\mathrm{Gem} / \mathrm{S} 1$ therapy is limited to $30 \%$, and the median survival time is only 10.1 months [5].

Transcriptional factor, nuclear factor kappa B $(\mathrm{NF}-\mathrm{\kappa B})$ plays an important role in the regulation of cell proliferation, inflammation and oncogenesis [6], and constitutive NF- $\mathrm{KB}$ activation leads to the aggressive behavior of pancreatic cancer [7, 8]. In addition, many anti-cancer agents including gemcitabine induce NF- $\mathrm{\kappa B}$ activation, which aggravates chemoresistance in cancer cells [9]. Therefore, control of chemotherapy-induced NF$\kappa \mathrm{B}$ activation could potentially enhance chemosensitivity. $\mathrm{NF}-\kappa \mathrm{B}$ consists of heterodimetric complex made up of the p65 (RelA) and p50 proteins, and normally presents in the cytoplasm as an inactive form with an inhibitor of NF- $\mathrm{KB}$ $(\mathrm{I} \kappa \mathrm{B} \alpha)[10]$. NF- $\kappa \mathrm{B}$ activators including anticancer agents trigger the pathway run-through of I $\kappa \mathrm{B} \alpha$ phosphorylation by I $\kappa \mathrm{B}$ kinase (IKK) complex, and NF- $\kappa \mathrm{B}$ release from I $\kappa \mathrm{B} \alpha$. The released NF- $\kappa \mathrm{B}$ translocates into the nucleus and initiates target gene transcription and expression, including anti-apoptotic proteins such as cleaved inhibitor of apoptosis 1 (cIAP1), cIAP2, X-linked inhibitor of apoptosis, and Survivin [11]. We previously reported that nafamostat mesilate, a synthetic serine protease inhibitor, inhibited gemcitabine-induced activation of NF- $\mathrm{kB}$ and increased chemosensitivity to gemcitabine and cell apoptosis in pancreatic cancer [12].

Pomalidomide is one of the third generation immunomodulating drugs (IMiDs), which is derived from thalidomide and has been approved in the United States for the treatment of relapsed or refractory multiple myeloma [13]. Anticancer effects of IMiDs in hematologic malignancies have been reported including suppression of angiogenesis, as well as immunomodulation and inhibition of cytokine production [14]. For multiple myeloma, pomalidomide induced $\mathrm{G} 0 / \mathrm{G} 1$ cell cycle arrest by upregulating the expression of p21 wafl [15], anti-angiogenesis by multiple inhibition of endothelial cell function [16] and apoptosis through upregulation of caspase- 8 by inhibiting the expression of IAP2 and tumor necrosis factor (TNF)-related ligand [17]. Furthermore, thalidomide, a predecessor of pomalidomide, exerts suppression of NF- $\mathrm{KB}$ activation and apoptosis induction via caspase cascade [18]. Although a few reports described pomalidomide as a NF- $\kappa \mathrm{B}$ inhibitor in multiple myeloma, the role of pomalidomide in pancreatic cancer has not been investigated.

The purpose of this study is to demonstrate that pomalidomide enhances chemosensitization of pancreatic cancer by inhibition of Gem/S1-induced NF- $\mathrm{KB}$ activation in vitro and in vivo.

\section{RESULTS}

\section{Pomalidomide improved chemosensitivity in human pancreatic cancer cells.}

To investigate the effect of pomalidomide monotherapy on cell proliferation in pancreatic cancer, we examined cell viabilities by MTT assay. Although low dose of pomalidomide $(10 \mu \mathrm{M})$ had anti-proliferative effects only in MIA PaCa-2 cells, the concentration $(100 \mu \mathrm{M})$ used in myeloma experiment and high dose $(1 \mathrm{mM})$ of pomalidomide demonstrated anti-proliferative effects in both pancreatic cancer cells (Figure 1A, 1B). Next, we examined cell viabilities after the treatment with $\mathrm{Gem} / \mathrm{S} 1$ with or without pomalidomide to verify the additive effect of pomalidomide. In results, pomalidomide enhanced $\mathrm{Gem} / \mathrm{S} 1$ therapy-induced anti-proliferative effects in both cell lines $(p<0.01$ each) (Figure 1C, 1D). These indicated that high dose of pomalidomide showed the anti-proliferative effects and improved chemosensitivity of human pancreatic cancer cells. In addition, we calculated combination index $(\mathrm{CI})$ between gemcitabine and pomalidomide (data not shown). In both cell line, CI was over 1, which suggested that pomalidomide has only additive effects.

\section{Enhancement of apoptosis signals and induction of apoptosis by pomalidomide}

To clarify the mechanism of the improvement of chemosensitization to Gem/S1-induced anti-proliferative effect by pomalidomide, we next analyzed induction of apoptosis signals by Western blots and flow cytometry. Firstly, we examined the effect of pomalidomide monotherapy on the expression levels of cleave caspase- 8 and -3 (Figure 2A). In results, pomalidomide monotherapy did not show clear effects of apoptosis induction. On the contrary, in combination therapy, pomalidomide enhanced the expression levels of cleaved caspase- 8 and cleaved caspase-3 protein in $\mathrm{Gem} / \mathrm{S} 1 /$ Pomalidomide group compared with that in $\mathrm{Gem} / \mathrm{S} 1$ group (Figure 2B). Subsequently, we measured the cell population of sub-G1 cells using cell cycle analysis, which indicated apoptotic cells. As a result of induction of apoptosis signals, Gem/ S1/Pomalidomide group had the largest sub-G1 cell population (Figure 2C). These indicated that pomalidomide monotherapy had little effects on cell apoptosis, whereas addition of pomalidomide to $\mathrm{Gem} / \mathrm{S} 1$ therapy increased 
Gem/S1-induced expression levels of apoptosis signals and apoptotic cells.

\section{Pomalidomide inhibited anti-cancer agents- induced $\mathrm{NF}-\mathrm{KB}$ activation}

To investigate more details of apoptosis induction, we examined the role of pomalidomide associated with NF- $\kappa B$ activation, which increases the expression of anti-apoptotic proteins. As the localization of nucleus in the pancreatic cancer cells reflects NF- $\kappa B$ activation, the concentration of $\mathrm{p} 65$, the subunit of NF- $\kappa \mathrm{B}$ dimers, in the nuclear extracts were measured. In vitro, anti-cancer agents $(\mathrm{Gem}$ or $\mathrm{Gem} / \mathrm{S} 1)$ increased the activation of NF$\kappa \mathrm{B}$ at 2 hours after treatment in both cell lines $(p<0.05$ and $p<0.01$, respectively) (Figure 3A). On the contrary, pomalidomide strongly inhibited the translocation of NF- $\kappa \mathrm{B}$ from the cytoplasm into the nucleus in pancreatic cancer cells $(p<0.01)$. Furthermore, pomalidomide inhibited anti-cancer agents-induced NF- $\kappa \mathrm{B}$ activation $(p<0.01)$. To investigate more details of the inhibitory mechanism of NF- $\kappa \mathrm{B}$ activation by pomalidomide, we evaluated the expression levels of selective upstream molecules such as $\mathrm{I} \kappa \mathrm{B} \alpha$ base and phosphorylated I $\mathrm{B} \alpha$ (Figure $3 \mathrm{~B}$ ). Although the levels of $\mathrm{I} \kappa \mathrm{B} \alpha$ base were comparable between Gem/S1 and Gem/S1/Pomalidomide, pomalidomide decreased the expression levels of phosphorylated I $\kappa \mathrm{B} \alpha$. These results suggested that pomalidomide inhibits phosphorylation of $\mathrm{I} \kappa \mathrm{B} \alpha$ and subsequently suppresses NF- $\kappa \mathrm{B}$ activation. In results, pomalidomide enhanced Gem/S1 therapy-induced cell apoptosis and antiproliferative effects in pancreatic cancer cells.

\section{Pomalidomide enhanced anti-tumor effect of Gem/S1 in orthotopic xenograft mouse model}

To assess the anti-tumor activity by Gem/S1 with pomalidomide in vivo, nude mice bearing xenograft were randomly divided into four groups (Control, Pomalidomide, Gem/S1, and Gem/S1/Pomalidomide). Single-treatment of pomalidomide showed only a mild anti-tumor effect in a mice model, while Gem/S1 therapy suppressed tumor growth compared with control $(p<0.05)$ (Figure 4A, 4B). Furthermore, pomalidomide enhanced anti-tumor effect of Gem/S1 $(p<0.05)$. After 6 weeks of these treatments, the tumor weight in Gem/ $\mathrm{S} 1 /$ Pomalidomide group were reduced by more than $50 \%$ of that in Gem/S1 group. There were no significant differences in the body weight of the animals among the four groups (Figure 4C). We also assessed the effect of those treatments on hemoglobin $(\mathrm{Hb})$ and platelets. Although Gem/S1 and Gem/S1/Pomalidomide groups
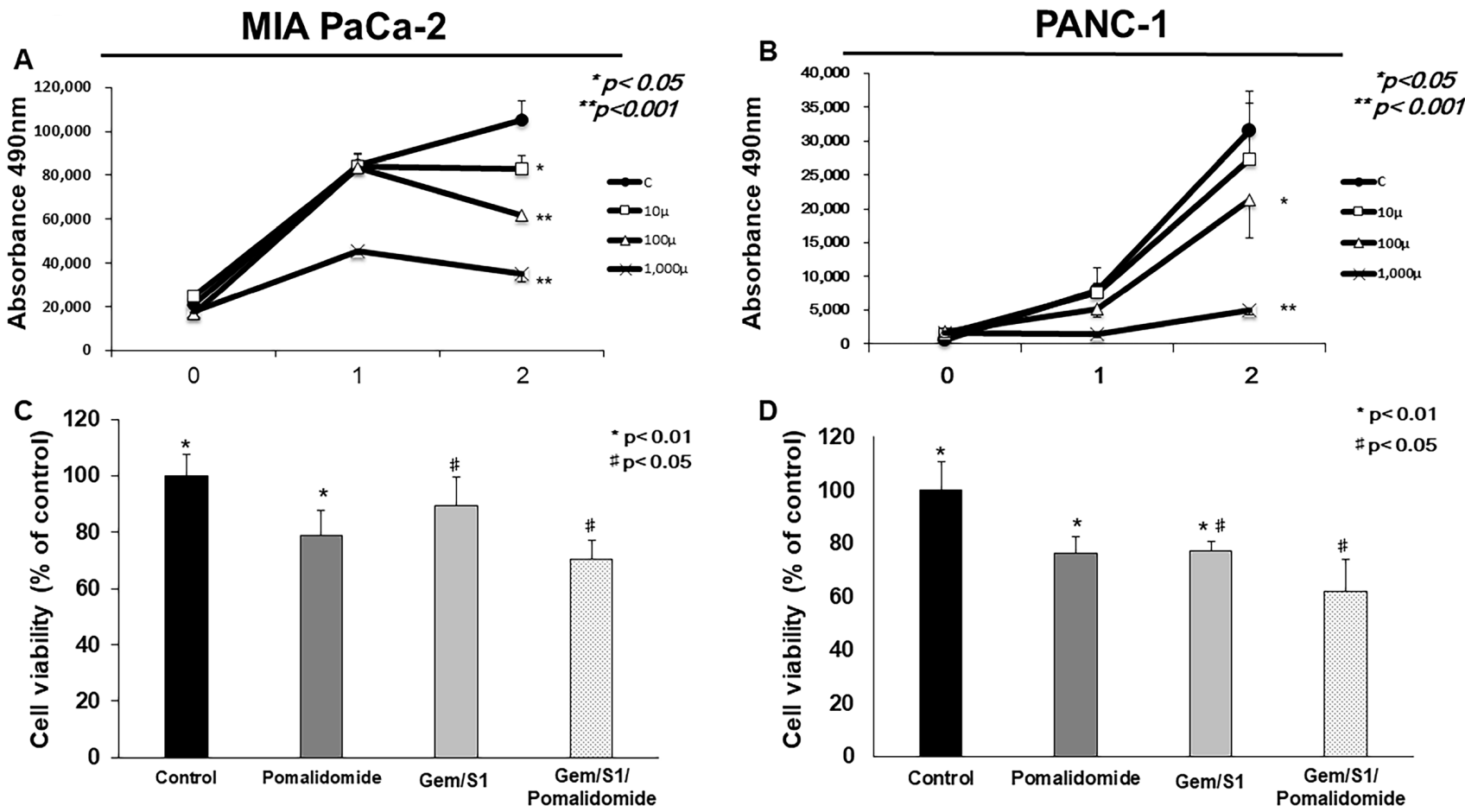

Figure 1: The cell viabilities of MIA PaCa-2 and PANC-1 cells were measured by the MTT assay. (A, B) Pomalidomide monotherapy $(100 \mu \mathrm{M}$ and $1 \mathrm{mM})$ showed antiproliferative effects in 48 hours $(p<0.05$ and $p<0.001$, respectively). The cell viabilities in the $\mathrm{Gem} / \mathrm{S} 1 /$ Pomalidomide were less than those in $\mathrm{Gem} / \mathrm{S} 1$ (C) MIA PaCa-2: $70.5 \pm 6.7$ vs. $89.3 \pm 10.2 \%, p<0.05$, (D) PANC-1: 62.2 \pm 11.8 vs. $77.2 \pm 10.7 \%, p<0.01$ 
demonstrated anemia $(p<0.01)$, Hb was comparable between Gem/S1 and Gem/S1/Pomalidomide groups (Figure 4D). The platelet counts in Gem/S1/Pomalidemide group was higher than that in control or Gem/S1 group $(p<0.05)$ (Figure 4E).

\section{Pomalidomide enhanced anticancer agents- induced tumor suppressor in vivo}

The effects of pomalidomide on NF- $\mathrm{KB}$ activation and apoptosis in pancreatic tumor were assessed using resected specimens. To verify the in vitro findings regarding the roles of pomalidomide, in vivo expression levels of apoptosis-related proteins and NF- $\kappa \mathrm{B}$ activation were assessed. Consistent with the in vitro data, these protein expression patterns in xenograft tumors treated with $\mathrm{Gem} / \mathrm{S} 1 /$ Pomalidomide showed a pattern similar to those observed in vitro (Figure $5 \mathrm{~A}$ ).

The TUNEL assay of the removed tumor that stain apoptotic cell demonstrated striking similarity with our in vitro study result that addition of pomalidomide further potentiated apoptosis induced by $\mathrm{Gem} / \mathrm{S} 1$ (Figure $5 \mathrm{C}$ ). Indeed, when the number of TUNEL positive cells was counted, not only Gem/S1 demonstrated significantly more apoptotic cells, but addition of pomalidomide demonstrated significantly more apoptotic cells compared from Gem/S1 alone (Figure 5D). Similar to in vitro experiments, pomalidomide also suppressed the activation of NF- $\kappa \mathrm{B}$ (Figure $5 \mathrm{~B}$ ). Immunohistochemical staining of Ki-67 showed that pomalidomide alone demonstrated significant suppression of cancer cell proliferation as well as Gem/S1 alone group (Figure 5E). Addition of pomalidomide to Gem/S1 demonstrated further significant suppression of cell proliferation, which implicate that Gem/S1/Pomalidomide combination therapy not only significantly increase apoptosis, but also suppress cancer cell proliferation.

\section{DISCUSSION}

For the last two decades, gemcitabine has been the standard regimen for unresectable pancreatic cancer. Only recently, FOLFIRINOX (oxaliplatin, irinotecan, fluorouracil, and leucovorin) has been reported to be superior to gemcitabine monotherapy in 2011 [19]. The combination therapy of gemcitabine and nab-paclitaxel also had superiority over gemcitabine alone [20]. Also, the advantage of combination chemotherapy of gemcitabine and S1 over gemcitabine alone for advanced pancreatic cancer has been reported [5]. Improving these

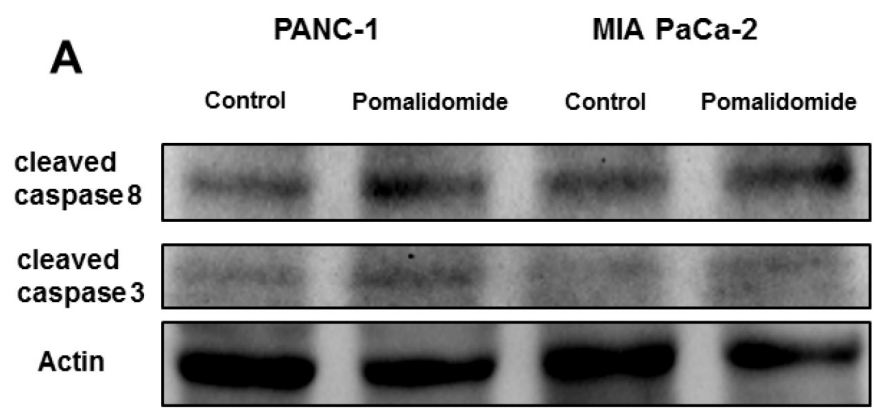

B

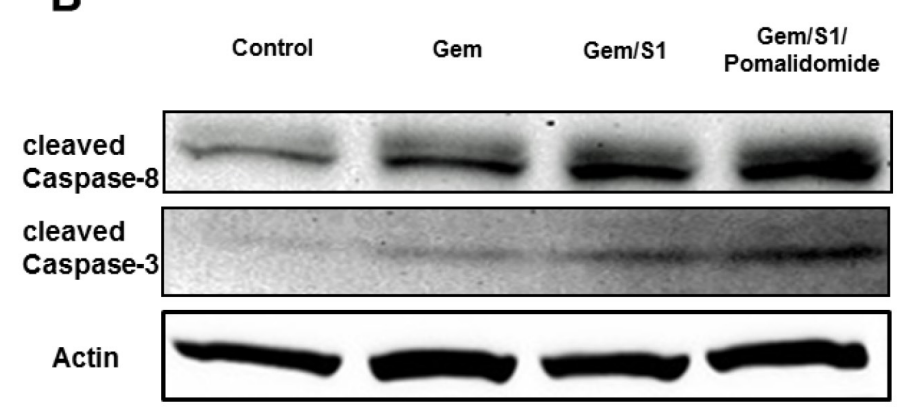

C
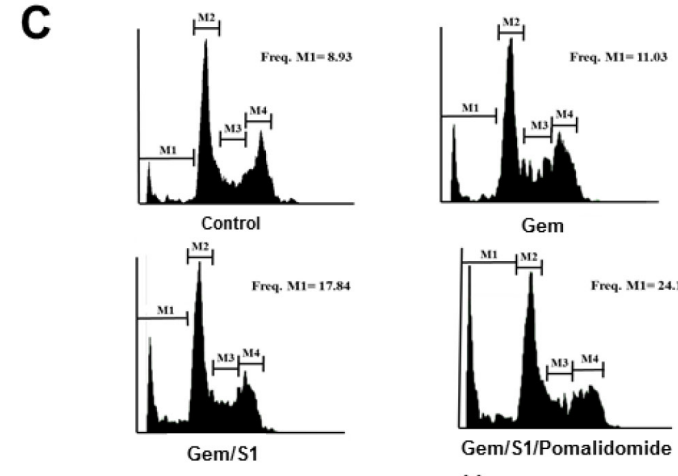

Gem
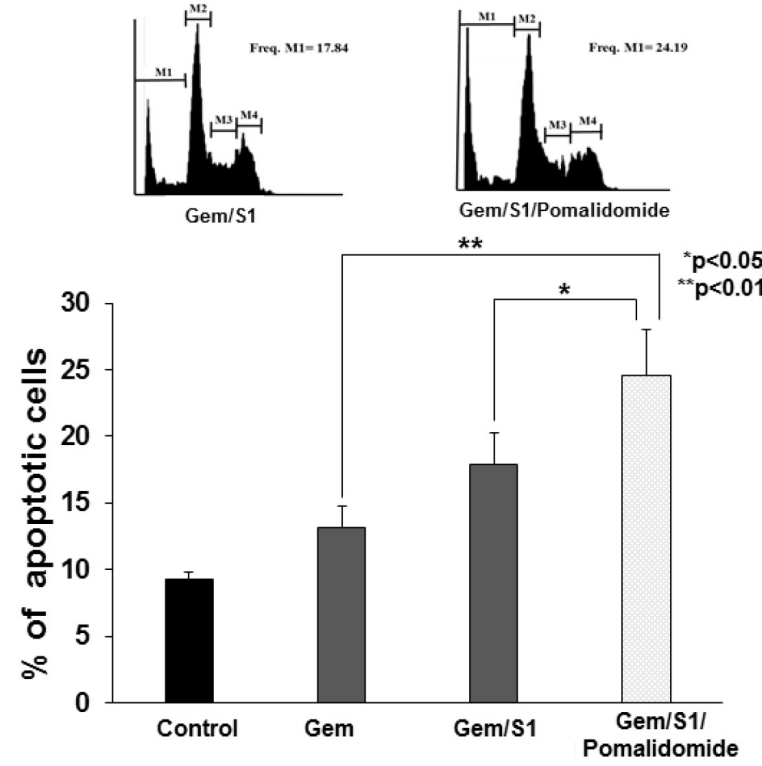

Figure 2: Western blot analysis demonstrated the expression levels of protein related to apoptosis signals at 24 hours. (A) The expression levels of cleaved caspase-8 and -3 were comparable between those with or without pomalidomide. (B) Gem/S1/ Pomalidomide increased the expression levels of cleaved caspase-8 and -3. (C) Cell cycle analysis showed apoptosis cells after each treatment for 48 hours. M1, M2, M3, and M4 signify sub-G1, G0/G1, S, and G2/M phases, respectively. Gem/S1/Pomalidomide had the largest apoptotic cell population, which was larger than $\mathrm{Gem} / \mathrm{S} 1(24.6 \pm 3.4$ vs. $17.9 \pm 2.4 \%, p<0.05)$. 


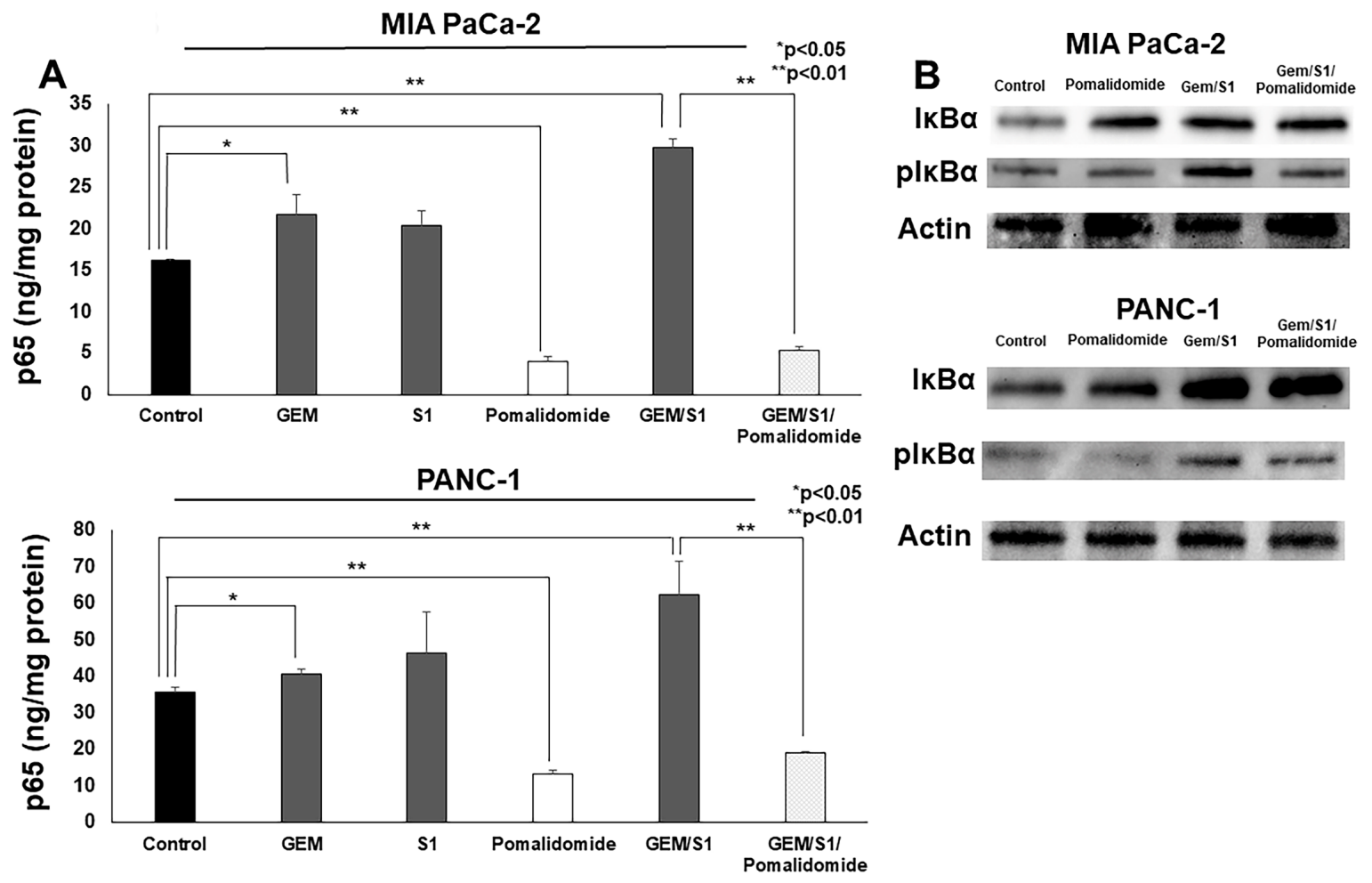

Figure 3: (A) The ELISA assay revealed that the NF- $\kappa$ B p65 concentration of MIA PaCa-2 and PANC-1 cells treated with Gem or Gem/ S1 for 2 hours were higher than control $(p<0.05)$, whereas pomalidomide decreased the $\mathrm{p} 65$ concentration compared with control group at 2 hours $(p<0.01)$. p65 concentration in Gem/S1/Pomalidomide was less than that in $\mathrm{Gem} / \mathrm{S} 1(p<0.01)$. (B) Western blots showed that the expression levels of phosphorylated $\mathrm{I} \kappa \mathrm{B} \alpha$ were decreased in pomalidomide administrated group.

A
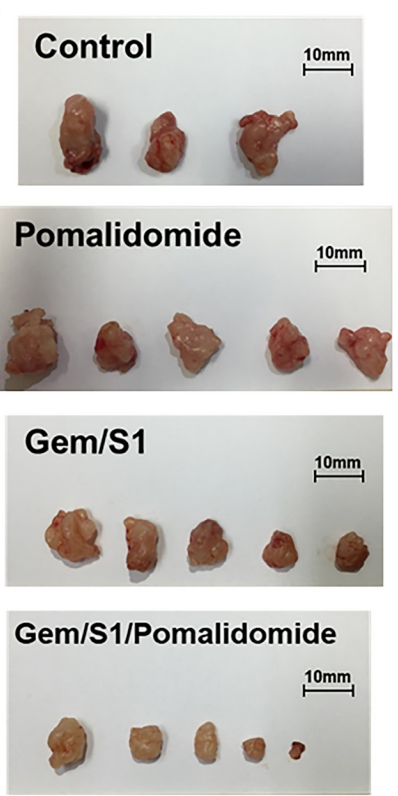
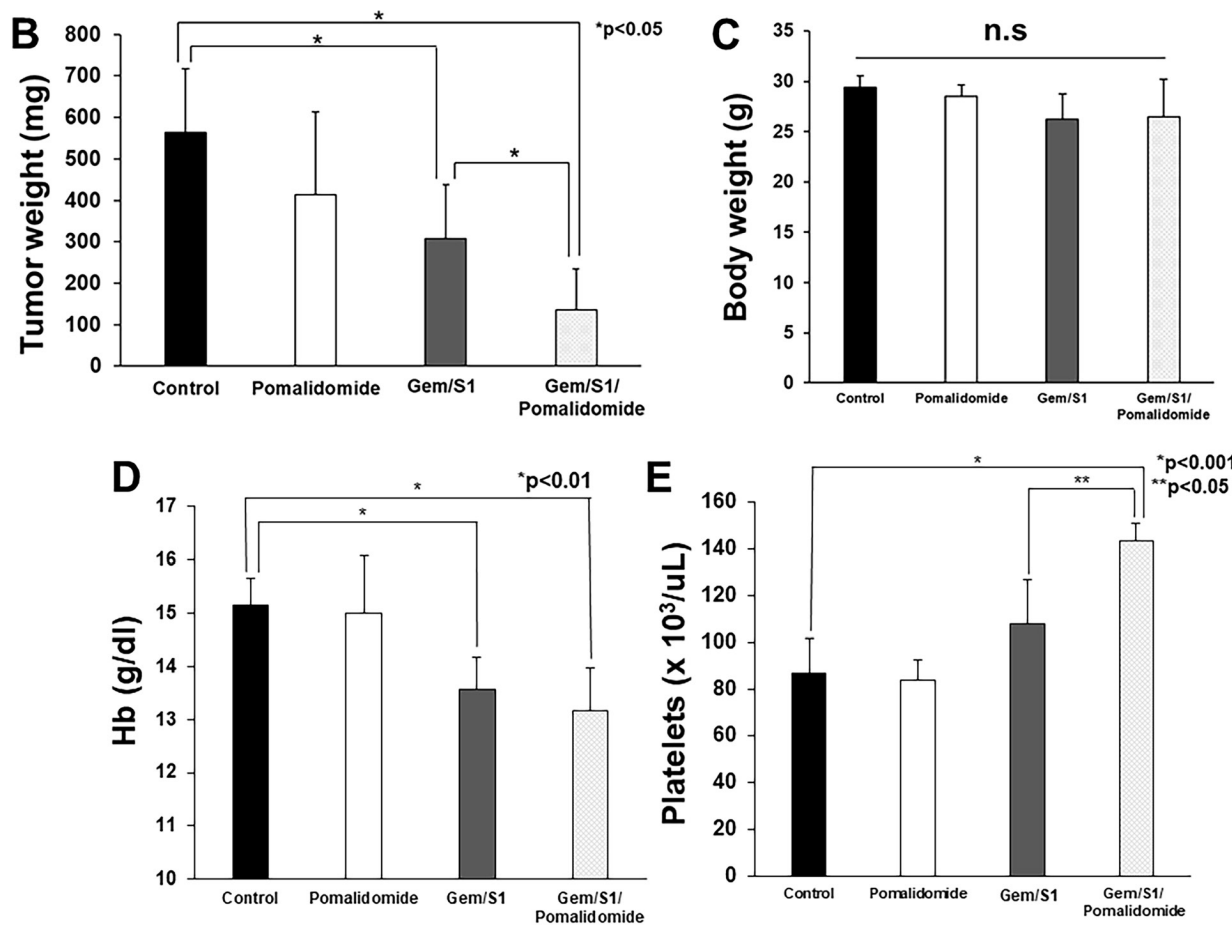

Figure 4: (A) Gem/S1/Pomalidomide had the smallest tumors after 6 weeks of treatment. (B) The excised tumor weight in Gem/S1/ Pomalidomide was lower than Gem/S1 (137.2 \pm 98.4 vs. $308.6 \pm 128.7 \mathrm{mg}, p<0.05)$. (C) Body weight after 6 weeks of treatment was comparable in 4 groups. (D) Hemoglobin in Gem/S1 with and without pomalidomide were lower than that in control $(\mathrm{Gem} / \mathrm{S} 1 \mathrm{vs.} \mathrm{Gem/}$ S1/Pomalidomide vs. Control $=13.6 \pm 0.5$ vs. $13.2 \pm 0.8$ vs. $15.5 \pm 0.5, p<0.01)$. (E) The platelet counts in $\mathrm{Gem} / \mathrm{S} 1 /$ Pomalidomide was higher than that in control $(p<0.001)$ or GEM/S1 $(p<0.05)$. 
treatment with NF- $\kappa$ B inhibitors could be a new standard therapy for unresectable pancreatic cancer. There were several clinical reports of combination therapy targeting $\mathrm{NF}-\kappa \mathrm{B}$ for pancreatic cancer by using NF- $\kappa \mathrm{B}$ inhibitors such as a curcumin [21], nafamostat mesilate [22, 23], bortezomib [24], thalidomide [25], and lenalidomide [26]. These clinical trials had acceptable outcomes. We previously reported that combination chemotherapy of gemcitabine and nafamostat mesilate, a NF- $\kappa$ B inhibitor, had favorable outcomes for unresectable pancreatic cancer in phase 1 and 2 study [22, 23]. However, nafamostat mesilate did require intra-arterial administration via a reservoir port, which necessitates infusion therapy at a hospital or outpatient clinic. On the other hands, as pomalidomide is orally administered, which could significantly reduce physical and financial burden to patients. Therefore, we selected pomalidomide as a novel NF- $\kappa \mathrm{B}$ inhibitor for the combination chemotherapy. Although phase 1 clinical trial about combination therapy of pomalidomide and gemcitabine was performed [27], the correlation between NF- $\kappa B$ and pomalidomde was not clear.
Thalidomide, the first generation IMiDs, suppresses $\mathrm{NF}-\kappa \mathrm{B}$ activation via inhibition of $\mathrm{I} \kappa \mathrm{B} \alpha$ phosphorylation [18]. In the present study, we found that pomalidomide which is a third generation IMiDs derived from thalidomide has similar effect on I $\kappa \mathrm{B} \alpha$ phosphorylation in pancreatic cancer cells. Furthermore, pomalidomide enhanced gemcitabine and S1-induced apoptotic signals and apoptosis. Consequently, pomalidomide demonstrated enhanced gemcitabine and S1-induced antitumor effects in vivo, suggesting that triple combination therapy of gemcitabine, S1 and pomalidomide had a synergistic anticancer effect on pancreatic cancer. To our knowledge, this is the first report of novel function of pomalidomide as an NF- $\mathrm{KB}$ inhibitor in non-hematologic malignancies.

Pomalidomide monotherapy demonstrated significant anti-proliferative effect in vitro and mild anti-tumor effect in vivo. However, pomalidomide monotherapy have no effects on induction of apoptosis. We hypothesized that other effects of pomalidomide which were reported previously such as anti-angiogenesis, immunomodulation, or cell cycle arrest may function in this study. Immunohistochemical staining showed that Ki-67 positive cells were decreased in

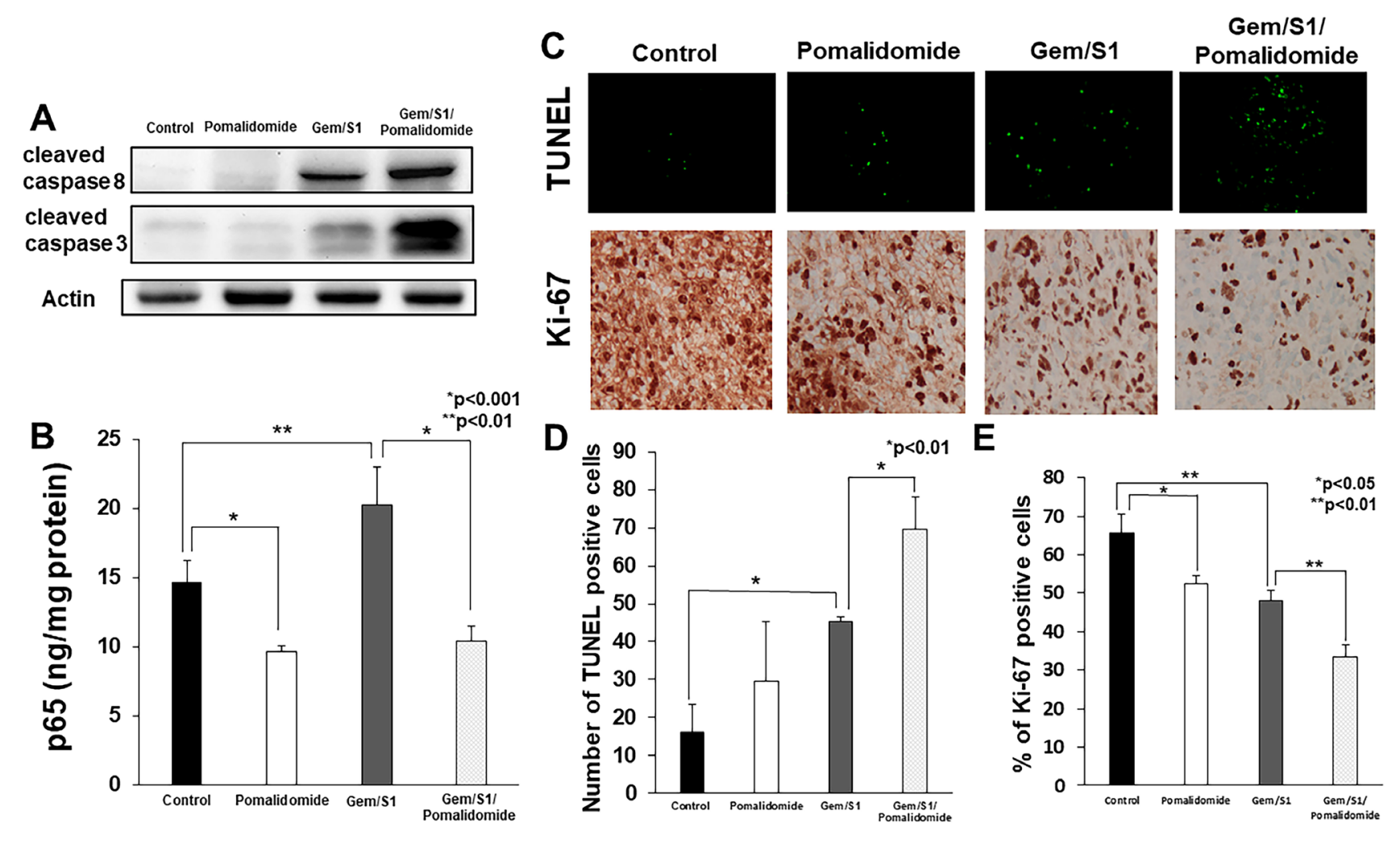

Figure 5: (A) Western blot analysis demonstrated the expression of apoptosis-related proteins in the excised tumor tissues. The expression levels of cleaved caspase- 8 and -3 in Gem/S1/Pomalidomide were higher than those in the other groups. (B) In assessment of NF- $\mathrm{kB}$ p65 activation by ELISA, the concentration of p65 in the nuclear extract of excised tumor tissues in pomalidomide group was lower than control $(p<0.001)$, whereas the level of $\mathrm{p} 65$ was greater in $\mathrm{Gem} / \mathrm{S} 1(p<0.01)$. In $\mathrm{Gem} / \mathrm{S} 1 /$ Pomalidomide, p65 concentration was lower than that in Gem/S1 $(p<0.001)$. (C) In TUNEL staining of the excised tumor tissues, (D) the number of TUNEL-positive cells in the $\mathrm{Gem} / \mathrm{S} 1 /$ Pomalidomide was greater than that in $\mathrm{Gem} / \mathrm{S} 1(69.7 \pm 8.4 \mathrm{vs} .45 .3 \pm 1.2, p<0.01)$. (E) The percentage of Ki-67-positive cells in Pomalidomide was lower than those in control (52.6 \pm 2.1 vs. $65.6 \pm 4.9 \%, p<0.05)$, and those in Gem/S1/Pomalidiomide was lower than those in $\mathrm{Gem} / \mathrm{S} 1(33.4 \pm 3.3$ vs. $48.1 \pm 2.5 \%, p<0.01)$, respectively. 
pomalidomide monotherapy group compared with control (Figure 5C, 5E), which suggested that pomalidomide induced cell cycle arrest in pancreatic cancer. In these points, the effects of pomalidomide remain unclear in pancreatic cancer, so further studies are required.

Pomalidomide originally has been used for multiple myeloma with dexamethasone. The safety of pomalidomide has been validated in several clinical trials. Therefore, this combination therapy could easily be applicable to clinical practice. Several adverse effects have been reported in the combination with pomalidomide and dexamethasone for the patients with multiple myeloma. The most common grade 3 or 4 toxicities were primarily neutropenia, which occurred in $32-65 \%$ of the patients [28-30]. Other hematological grade adverse effect was anemia in 5-36\% and thrombocytopenia in 3-31\% [28-30]. Venous thromboembolic events were reported as an important non-hematological adverse effect. Therefore, all patients receiving pomalidomide therapy were required to administer thromboprophylaxis, which reduced the rate of venous thromboembolic events to $2-3 \%$ [28-30]. In the current study, both of combination therapy of Gem/ S1 with or without pomalidomide showed anemia by 6 weeks of therapy, but there were no significant differences between Gem/S1 with pomalidomide and Gem/S1 group (Figure 4D). On the contrary, Gem/S1/Pomalidomide therapy demonstrated thrombocytosis, which suggested thrombotic tendency (Figure 4E). Therefore, the patients with pancreatic cancer may require thromboprophylaxis during the therapy.

In summary, the current study demonstrated that pomalidomide enhanced Gem/S1-induced cell apoptosis by inhibiting NF- $\mathrm{KB}$ activation in pancreatic cancer in vitro and in vivo. IMiDs could be a novel potential option for chemotherapy in pancreatic cancer.

\section{MATERIALS AND METHODS}

\section{Cell culture}

Human pancreatic cancer cell lines MIA PaCa2 and PANC-1 were purchased from American Type Culture Collection (Rockville, MD, USA). Both cell lines were maintained in Dulbecco's modified Eagle's Medium (DMEM) containing 10\% fetal bovine serum (Thermo Fisher Scientific, Rockville, MD, USA) and 1\% penicillin/ streptomycin (Thermo Fisher Scientific). The cells cultured at $37^{\circ} \mathrm{C}$ with $5 \% \mathrm{CO}_{2}$. Cells were given fresh media before treatment.

\section{Reagents}

Pomalidomide (Sigma-Aldrich Corp., Missouri, USA) was dissolved in DMSO $(10 \mathrm{mg} / \mathrm{ml})$ and stored at $-80^{\circ} \mathrm{C}$ until use. S1 contains a combination of FT (5-fluoro-1(tetrahydro-2-furfuryl) uracil, Tokyo Chemical Industry,
Tokyo, Japan) and Gimeracil (5-chloro-2, 4-diharroxypridine, Tokyo Chemical Industry) at a molar ratio of 1:0.4 dissolved in $0.5 \%$ hydroxypropylmethylcellolose (HPMC; ShinEtsu Chemical Co., Ltd., Tokyo, Japan). Gemcitabine was purchased from Eli Lilly Japan (Tokyo, Japan).

\section{Antibodies}

Antibodies specific to cleaved caspase- 8 and -3 were obtained from Cell Signaling Technology (Beverly, MA, USA). Anti- $\beta$-actin antibody was purchased from Sigma Chemical (St. Louis, MO, USA).

\section{In vitro experimental treatment groups}

On the basis of previous study, MIAPaCa-2 and PANC-1 cells were treated with gemcitabine $(10 \mathrm{nM})$ (Gem), both gemcitabine $(10 \mathrm{nM})$ and $\mathrm{S} 1(0.25 \mu \mathrm{g} / \mathrm{ml})$ (Gem/S1), gemcitabine (10 nM), S1 $(0.25 \mu \mathrm{g} / \mathrm{ml})$, and pomalidomide $(100 \mu \mathrm{M})(\mathrm{Gem} / \mathrm{S} 1 /$ Pomalidomide), and vehicle-only (control) for the appropriate time in each analysis [31]. In Gem/S1/Pomalidomide group, pancreatic cancer cells were treated with pomalidomide for 2 hours before gemcitabine and S1 treatment.

\section{Animals and in vivo orthotopic experimental models}

Five-week-old male nude mice (BALBc nu/nu) purchased from CLEA Japan Inc. (Tokyo, Japan) were housed under specific pathogen-free conditions in a biologic cabinet at the Laboratory Animal Facility of The Jikei University School of Medicine. We established an orthotopic pancreatic cancer xenograft model in mice by injection of $5.0 \times 10^{6}$ PANC- 1 cells suspended in $50 \mu \mathrm{L}$ of phosphate buffer saline (PBS) into the tail of the pancreas. At 5 weeks after injection, the animals were treated with oral administration of pomalidomide $(0.5 \mathrm{mg} / \mathrm{kg})$ three times a week (Pomalidomide group), intravenous (i.v.) injection of Gemcitabine $(100 \mathrm{mg} / \mathrm{kg})$ once a week in condition with oral administration of S1 $(10 \mathrm{mg} / \mathrm{kg})$ three times a week (Gem/S1 group), or combination therapy of Gemcitabine, $\mathrm{S} 1$, and pomalidomide (Gem/S1/Pomalidomide group). For control group, the equal amount of distilled water was injected (i.v.) weekly and 5\% of DMSO (p.o.) three times a week. To measure full blood counts as the toxicity of treatment by Celltac $\alpha$ MEK-6358 (NIHON KOHDEN, Tokyo, Japan), blood samples were taken at 6 weeks after treatment. At 6 weeks after treatment, the animals were humanely killed and the pancreatic tumor were excised. This research was approved by the Institutional Animal Care and Use Committee of The Jikei University School of Medicine (2015-002). 


\section{Cell proliferation assay}

Pancreatic cancer cells were seeded into 96-wells plates $\left(5 \times 10^{3}\right.$ cells in each well), and were incubated with each treatment for appropriate time. Cell proliferation was measured using a CellTiter-blue Cell Viability Assay Kit (Promega, Madison, WI) according to the manufacturer's instructions. Combination index (CI) was calculated [32].

\section{Western blot analysis}

Lysate protein was extracted from whole-cells $\left(5 \times 10^{6}\right.$ cells for each) after each treatment for 24 hours in vitro and from excised tumor tissue after treatment in vivo. This protocol for Western blot analysis was described in a previous study [33]. After incubating the blots in each primary antibody (1:1,000 dilution) overnight, membranes were incubated with peroxidase-labeled secondary antibody (1:10,000 dilution, Histofine; Nichirei, Tokyo, Japan) for 2 hours and detected by using Clarity Max Western ECL Substrate (BIO-RAD, Hercules, CA, USA). Protein bands were detected using a Chemi Doc XRS+ system and Image Lab Softwear (BIO-RAD).

\section{Cell cycle analysis}

After treatment with each regimen for 48 hours, $1 \times 10^{5}$ cells were harvested and fixed in $70 \%$ ethanol and stored at $-20^{\circ} \mathrm{C}$ for at least 24 hours. After centrifugation, the cells were washed with PBS, and re-suspended in PBS with RNase for 4 min at $4^{\circ} \mathrm{C}$. DNA was stained with propidium iodide solution (Sigma-Aldrich, St. Louis, MO, USA) for 30 minutes in the dark at $4^{\circ} \mathrm{C}$. DNA content was determined with a MACSQuant R Analyzer (Miltenyi Biotec K.K., Tokyo, Japan). The data were analyzed with MACSQuantify ${ }^{\mathrm{TM}}$ Softwear version.2.5.

\section{Quantitative analysis of NF- $\kappa$ B activity}

For assessment of NF- $\mathrm{KB}$ activity in each treatment group, the concentration of NF- $\mathrm{kB}$ p65 in the nuclear extracts was measured in vitro and in vivo. Nuclear extracts of treated pancreatic cells were prepared using a nuclear extract kit (Active Motif, Carlsbad, CA, USA) according to the manufacturer's protocol. The nuclear extracts were assessed using an enzyme-linked immunosorbent assay (ELISA) kit (TransAM ${ }^{\mathrm{TM}} \mathrm{NF}-\kappa B$; Active Motif) to detect and quantify the NF- $\kappa \mathrm{B}$ activity according to the manufacturer's instruction.

\section{Immunohistochemical staining}

Paraffin sections of tumor tissue were stained immunohistochemically using Ki-67 antibody (1:300) and visualized using BenchMark-XT (VENTANA Medical System, Tuson, AZ, USA). TUNEL assay was performed to evaluate the induction of apoptosis with
In Situ Cell Death Detection Kit (Roche Diagnostics, Basel, Swiss). The percentage of Ki-67 positive cells was microscopically examined in 3 random high-power fields at $400 \times$ from three tumors. The TUNEL-positive cells were counted at $200 \times$.

\section{Statistical analysis}

Data were expressed as a mean $\pm \mathrm{SD}$. Non-paired 2 -tailed $t$-test was used for statistical analysis. All $P$ value were considered statistically significant at $<0.05$.

\section{Abbreviations}

Gem: gemcitabine; NF-кB: nuclear factor kappa $\mathrm{B}$; ІкB $\alpha$ : inhibitor of kappa B; IKK: IкB kinase; IAP: inhibitor of apoptosis; IMiDs; immunomodulatory drugs; TNF: tumor necrosis factor; PBS: phosphate buffer saline; ELISA: enzyme-linked immunosorbent assay.

\section{Author contributions}

YS performed in vivo and ELSA assay and was a major contributor in writing the manuscript. NS performed apoptosis and cell vibirity assay and was a major contributor in writing a manuscript. TU analyzed the data and revised the manuscprpt. HS and KY revised the manuscript and the figures. TH performed the immunohistochemical staining. RI and $\mathrm{KH}$ evaluated the data and performed stiatistical analysis.

\section{CONFLICTS OF INTEREST}

We have no conflicts of interest to declare.

\section{FUNDING}

This work was supported by JSPS KAKENHI (Grant Number 15K19911).

\section{REFERENCES}

1. Torre LA, Bray F, Siegel RL, Ferlay J, Lortet-Tieulent J, Jemal A. Global cancer statistics, 2012. CA Cancer J Clin. 2015; 65:87-108.

2. Werner J, Combs SE, Springfeld C, Hartwig W, Hackert T, Büchler MW. Advanced-stage pancreatic cancer: therapy options. Nat Rev Clin Oncol. 2013; 10:323-333.

3. Sirri E, Castro FA, Kieschke J, Jansen L, Emrich K, Gondos A, Holleczek B, Katalinic A, Urbschat I, Vohmann C, Brenner $H$. Recent trends in survival of patients with pancreatic cancer in Germany and the United States. Pancreas. 2016; 45:908-914.

4. Yanagimoto H, Ishii H, Nakai Y, Ozaka M, Ikari T, Koike K, Ueno H, Ioka T, Satoi S, Sho M, Okusaka T, Tanaka M, 
Shimokawa $\mathrm{T}$, et al. Improved survival with combined gemcitabine and S-1 for locally advanced pancreatic cancer: pooled analysis of three randomized studies. J Hepatobiliary Pancreat Sci. 2014; 21:761-766.

5. Ueno $\mathrm{H}$, Ioka $\mathrm{T}$, Ikeda M, Ohkawa S, Yanagimoto $\mathrm{H}$, Boku N, Fukutomi A, Sugimori K, Baba H, Yamao K, Shimamura T, Sho M, Kitano M, et al. Randomized phase III study of gemcitabine plus S-1, S-1 alone, or gemcitabine alone in patients with locally advanced and metastatic pancreatic cancer in Japan and Taiwan: GEST study. J Clin Oncol. 2013; 31:1640-1648.

6. Karin M. Nuclear factor-kappaB in cancer development and progression. Nature. 2006; 441:431-436.

7. Shirai Y, Shiba H, Iwase R, Haruki K, Fujiwara Y, Furukawa K, Uwagawa T, Ohashi T, Yanaga K. Dual inhibition of nuclear factor kappa-B and Mdm2 enhance the antitumor effect of radiation therapy for pancreatic cancer. Cancer Lett. 2016; 370:177-184.

8. Shirai Y, Uwagawa T, Shiba H, Shimada Y, Horiuchi T, Saito N, Furukawa K, Ohashi T, Yanaga K. Recombinant thrombomodulin suppresses tumor growth of pancreatic cancer by blocking thrombin-induced PAR1 and NF-kappaB activation. Surgery. 2017;161:1675-1682.

9. Wang CY, Cusack JC Jr, Liu R, Baldwin AS. Control of inducible chemoresistance: enhanced anti-tumor therapy through increased apoptosis by inhibition of NF-kappaB. Nat Med. 1999; 5:412-417.

10. O’Dea E, Hoffmann A. NF-kappaB signaling. Wiley Interdiscip Rev Syst Biol Med. 2009; 1:107-115.

11. Barkett M, Gilmore TD. Control of apoptosis by Rel/ NF-kappaB transcription factors. Oncogene. 1999; 18:6910-6924.

12. Uwagawa T, Chiao PJ, Gocho T, Hirohara S, Misawa T, Yanaga K. Combination chemotherapy of nafamostat mesilate with gemcitabine for pancreatic cancer targeting NF-kappaB activation. Anticancer Res. 2009; 29:3173-3178.

13. Elkinson S, McCormack PL. Pomalidomide: first global approval. Drugs. 2013; 73:595-604.

14. McCurdy AR, Lacy MQ. Pomalidomide and its clinical potential for relapsed or refractory multiple myeloma: an update for the hematologist. Ther Adv Hematol. 2013; 4:211-216.

15. Escoubet-Lozach L, Lin IL, Jensen-Pergakes K, Brady HA, Gandhi AK, Schafer PH, Muller GW, Worland PJ, Chan KW, Verhelle D. Pomalidomide and lenalidomide induce p21 WAF-1 expression in both lymphoma and multiple myeloma through a LSD1-mediated epigenetic mechanism. Cancer Res. 2009; 69:7347-7356.

16. Lu L, Payvandi F, Wu L, Zhang LH, Hariri RJ, Man HW, Chen RS, Muller GW, Hughes CC, Stirling DI, Schafer PH, Bartlett JB. The anti-cancer drug lenalidomide inhibits angiogenesis and metastasis via multiple inhibitory effects on endothelial cell function in normoxic and hypoxic conditions. Microvasc Res. 2009; 77:78-86.

17. Mitsiades N, Mitsiades CS, Poulaki V, Chauhan D, Richardson PG, Hideshima T, Munshi NC, Treon SP, Anderson KC. Apoptotic signaling induced by immunomodulatory thalidomide analogs in human multiple myeloma cells: therapeutic implications. Blood. 2002; 99:4525-4530.

18. Keifer JA, Guttridge DC, Ashburner BP, Baldwin AS. Inhibition of NF-kappa B activity by thalidomide through suppression of IkappaB kinase activity. J Biol Chem. 2001; 276:22382-22387.

19. Conroy T, Desseigne F, Ychou M, Bouché O, Guimbaud R, Bécouarn Y, Adenis A, Raoul JL, Gourgou-Bourgade S, de la Fouchardière $\mathrm{C}$, Bennouna J, Bachet JB, KhemissaAkouz F, et al, and Groupe Tumeurs Digestives of Unicancer, and PRODIGE Intergroup. FOLFIRINOX versus gemcitabine for metastatic pancreatic cancer. N Engl J Med. 2011; 364:1817-1825.

20. Von Hoff DD, Ervin T, Arena FP, Chiorean EG, Infante J, Moore M, Seay T, Tjulandin SA, Ma WW, Saleh MN, Harris M, Reni M, Dowden S, et al. Increased survival in pancreatic cancer with nab-paclitaxel plus gemcitabine. N Engl J Med. 2013; 369:1691-1703.

21. Kanai M, Yoshimura K, Asada M, Imaizumi A, Suzuki C, Matsumoto S, Nishimura T, Mori Y, Masui T, Kawaguchi Y, Yanagihara K, Yazumi S, Chiba T, et al. A phase I/II study of gemcitabine-based chemotherapy plus curcumin for patients with gemcitabine-resistant pancreatic cancer. Cancer Chemother Pharmacol. 2011; 68:157-164.

22. Uwagawa T, Misawa T, Sakamoto T, Ito R, Gocho T, Shiba H, Wakiyama S, Hirohara S, Sadaoka S, Yanaga K. A phase I study of full-dose gemcitabine and regional arterial infusion of nafamostat mesilate for advanced pancreatic cancer. Ann Oncol. 2009; 20:239-243.

23. Fujiwara Y, Shiba H, Iwase R, Haruki K, Furukawa K, Uwagawa T, Misawa T, Ohashi T, Yanaga K. Inhibition of nuclear factor kappa-B enhances the antitumor effect of combination treatment with tumor necrosis factor-alpha gene therapy and gemcitabine for pancreatic cancer in mice. J Am Coll Surg. 2013; 216:320-322.

24. Alberts SR, Foster NR, Morton RF, Kugler J, Schaefer P, Wiesenfeld M, Fitch TR, Steen P, Kim GP, Gill S. PS-341 and gemcitabine in patients with metastatic pancreatic adenocarcinoma: a North Central Cancer Treatment Group (NCCTG) randomized phase II study. Ann Oncol. 2005; 16:1654-1661.

25. Shi SB, Wang M, Niu ZX, Tang XY, Liu QY. Phase II trial of capecitabine combined with thalidomide in second-line treatment of advanced pancreatic cancer. Pancreatology. $2012 ; 12: 475-479$.

26. Infante JR, Arkenau HT, Bendell JC, Rubin MS, Waterhouse D, Jones GT, Spigel DR, Lane CM, Hainsworth JD, Burris HA 3rd. Lenalidomide in combination with gemcitabine as first-line treatment for 
patients with metastatic carcinoma of the pancreas: a Sarah Cannon Research Institute phase II trial. Cancer Biol Ther. 2013; 14:340-346.

27. Infante JR, Jones SF, Bendell JC, Spigel DR, Yardley DA, Weekes CD, Messersmith WA, Hainsworth JD, Burris HA. A phase I, dose-escalation study of pomalidomide (CC4047) in combination with gemcitabine in metastatic pancreas cancer. Eur J Cancer. 2011; 47:199-205.

28. Lacy MQ, Hayman SR, Gertz MA, Dispenzieri A, Buadi F, Kumar S, Greipp PR, Lust JA, Russell SJ, Dingli D, Kyle RA, Fonseca R, Bergsagel PL, et al. Pomalidomide (CC4047) plus low-dose dexamethasone as therapy for relapsed multiple myeloma. J Clin Oncol. 2009; 27:5008-5014.

29. Lacy MQ, Hayman SR, Gertz MA, Short KD, Dispenzieri A, Kumar S, Greipp PR, Lust JA, Russell SJ, Dingli D, Zeldenrust S, Fonseca R, Bergsagel PL, et al. Pomalidomide (CC4047) plus low dose dexamethasone (Pom/dex) is active and well tolerated in lenalidomide refractory multiple myeloma (MM). Leukemia. 2010; 24:1934-1939.
30. Leleu X, Karlin L, Macro M, Hulin C, Garderet L, Roussel M, Arnulf B, Pegourie B, Kolb B, Stoppa AM, Brechiniac S, Marit G, Thielemans B, et al, and Intergroupe Francophone du Myélome (IFM). Pomalidomide plus lowdose dexamethasone in multiple myeloma with deletion $17 \mathrm{p}$ and/or translocation $(4 ; 14)$ : IFM 2010-02 trial results. Blood. 2015; 125:1411-1417.

31. Morimoto Y, Takeuchi O, Takizawa A, Yoneyama H, Asanuma F, Suzuki Y, Atsuda K, Yamada Y. Effect of a combination of S-1 and gemcitabine on cell cycle regulation in pancreatic cancer cell lines. Anticancer Drugs. 2012; 23:505-514.

32. Chou TC. Theoretical basis, experimental design, and computerized simulation of synergism and antagonism in drug combination studies. Pharmacol Rev. 2006; 58:621-81.

33. Nishiyama Y, Shimada Y, Yokoi T, Kobayashi $H$, Higuchi T, Eto Y, Ida H, Ohashi T. Akt inactivation induces endoplasmic reticulum stress-independent autophagy in fibroblasts from patients with Pompe disease. Mol Genet Metab. 2012; 107:490-495. 